\title{
Involvement of PRCD and RPGR Genes in Progressive Retinal Atrophy in Locally Bred Canines
}

\section{Ushma Dave ${ }^{1 *}$ and Dave $\mathbf{C J}^{2}$}

'Department of Biotechnology, M B Patel Science College, Anand, 388001, India

'Department of Biotechnology, Veterinary Science College, Anand, 388001, India

\begin{abstract}
Progressive Retinal Atrophy is a group of genetically inherited diseases in various canine breeds. The disease begins with retinal damage and progresses to blindness. Abnormalities in various genes are linked with different disease variants, and in most cases, involvement of one gene towards PRA is specific to one breed. However, Progressive Rod Cone Degeneration (PRCD) is an outlier. PRCD anomaly is associated with PRA in more than 20 breeds. The same gene mutation which causes PRA-prcd in dogs causes a form of Retinitis Pigmentosa in human. X-Linked Progressive Retinal Atrophy (XLPRA); a type of PRA, is a result of deletion in Retinitis Pigmentosa GTPase Regulator (RPGR). RPGR is a locus homologue of human Retinitis pigmentosa (RP3). We analyzed 22 clinically PRA positive dog samples for PRCD and RPGR association with PRA. We employed PCR-RFLP, capillary gel electrophoresis and sequencing. Experiment data suggests that tested mutation of $P R C D$ has no association with PRA in all 15 Pomeranian and 1 Mongrel dogs which are locally bred by Indian breeders. In contrary, all English Cocker spaniel and Labrador Retriever samples showed $P R C D$ association with PRA. Furthermore, accountability of tested mutations in RPGR has been concluded to be nil in all of the test samples.
\end{abstract}

Keywords: Progressive retinal atrophy; XLPRA; PRCD; RPGR; Retinitis pigmentosa

\section{Introduction}

Progressive Retinal Atrophy (PRA) is a group of genetic diseases found in 100 plus canine breeds [1]. The typical characteristic of the disease is loss of night vision followed by gradual loss of peripheral vision leading to total blindness [1]. The disease causes great deal of discomfort in the breeding industry as well as to the owners as the disease is incurable. In addition, canine PRA has potential to serve as an animal model in human Retinitis Pigmentosa (RP) [2]. This is due to shared molecular defects and/or phenotypic similarities [3]. Thus, in the field of Veterinary science, it is critical to understand, avoid and eradicate PRA. Strong association of PRA with human RP promises to answer essential questions on the disease.

Complete ophthalmic diagnosis can identify later phase of the disease. However, earlier stages are not detected by this method. While Electroretinogram (ERG) can diagnose disease at early stages [4], it requires technological advances and expertise. In addition, animal needs to undergo anesthesia, which is a risky affair. Due these added complications, ERG is not the most preferred method for diagnosis of PRA.

In the canine care industry and the breeding industry in particular, it is critical that genetic diseases are diagnosed at the earliest to exclude affected and carrier dogs from breeding program. Such strategies can facilitate eradication of diseases. Molecular biology based diagnosis is a cost effective strategy in the current scenario.

The disease is found to be inherited in variety of transmission method engaging multiple genes and mutations [5]. The relations between particular disease causing gene anomalies and breed have been established. In most cases, one gene is associated to one flavor of disease in one breed [2]. However, as an exception, $P R C D$ is reported to be linked to more than 20 breeds [6].

$P R C D$ is located on CFA9 [7]. Mutation in PRCD can give rise to PRA-prcd. This happens when amino acid Cysteine is replaced by Tyrosin as a result of homozygous mutation TCG, TAC at nucleotide 5 of coding sequence [6]. In PRA-prcd, late onset degeneration starts from rod cells which progresses to con cells [8]. The inheritance pattern of the disease is autosomal recessive type. This is why it is important to test all dogs involved in breeding program, regardless their phenotype.

Deletion in gene Retinitis Pigmentosa GTPase Regulator (RPGR) can give rise to X-Linked variant of PRA in some breeds [9]. In exon ORF15 on X-chromosome, deletion of $2 \mathrm{bp}$ and $5 \mathrm{bp}$ in RPGR gene can lead to XLPRA1 and XLPRA2 correspondingly [5]. The five nucleotide deletion in XLPRA1 results in frame-shift, which leads to immediate premature stop codon. This is only true for Siberian husky and Samoyed yet. In Mongrel, two nucleotides deletion results in frame-shift. This further leads to significant changes in deduced peptide sequence [9] and disease phenotype. XLPRA1 is an early onset disease while XLPRA2 occurs at later age. The gene is canine homologue of Retinitis Pigmentosa [4]. Further, study reports that $R P G R$ is associated with impaired hearing and sinorespiratory infections, in addition to retinitis pigmentosa [10]. Added complications and link to human disease make this gene a good study candidate. As per Guyon et al. [11], dog is the only naturally occurring model of RPGR-XLPR.

In Pomeranian, relation of PRCD or RPGR to PRA is not yet established. In one effort [5] to ascertain RPGR to PRA relation, they found no such link for tested Pomeranian. In addition, their Pomeranian sample size was limited to 2 .

We aim to identify if there is an association with PRCD and/or RPGR gene mutation and PRA in sampled breeds.

*Corresponding author: Ushma Dave, Jain University, Nabobiosciences Bangalore, Karnataka 562112, India, Tel: +91 8971209696; E-mail: daveushma@yahoo.com

Received December 05, 2013; Accepted Januauary 15, 2014; Published Januauary 21, 2014

Citation: Dave U, Dave CJ (2014) Involvement of PRCD and RPGR Genes in Progressive Retinal Atrophy in Locally Bred Canines. J Mol Biomark Diagn 5: 161. doi:10.4172/2155-9929.1000161

Copyright: (C) 2014 Dave U, et al. This is an open-access article distributed under the terms of the Creative Commons Attribution License, which permits unrestricted use, distribution, and reproduction in any medium, provided the original author and source are credited 
Citation: Dave U, Dave CJ (2014) Involvement of PRCD and RPGR Genes in Progressive Retinal Atrophy in Locally Bred Canines. J Mol Biomark Diagn 5: 161. doi:10.4172/2155-9929.1000161

Page 2 of 4

\section{Materials and Methods}

\section{Clinical investigation/ophthalmologic examination}

22 dogs-15 Pomeranian, 3 Cocker spaniel, 3 Labrador Retriever and 1 Mongrel with history of vision loss were examined. Examination included various visual function tests such as menace response, papillary light response and tapetal response. Then the dogs were subjected to indirect ophthalmoscopy for fundus examination after dilation of pupil with mydriatics. If fundus examination revealed pale optic disc, the animal was considered clinically positive for PRA.

\section{DNA extraction from blood}

Blood samples from 22 PRA positive dogs (aged 2-15; mean age 8.7) were collected in LABTUBE (Lebtech disposables, India) containing EDTA. Blood DNA extraction was carried out following John (1991).

\section{Mutation analysis for PRCD gene by PCR-RFLP}

The exon1 of CFA9 was subjected to PCR amplification using sequence specific primers. These primers were selected from a reference article [3], primer sequence for forward primer was 5'CCAGTGGCAGCAGGAACC3', 5'CCGACCTGCTGCCCACGACTG3' for the reverse primer. PCR was carried out under the conditions of $95^{\circ} \mathrm{C}$ for $5 \mathrm{~min}$ and then $37 \mathrm{cycles}$ of $95^{\circ} \mathrm{C}$ for $45 \mathrm{sec}, 58^{\circ} \mathrm{C}$ for $35 \mathrm{sec}, 72^{\circ} \mathrm{C}$ for $35 \mathrm{sec}$ and $72^{\circ} \mathrm{C}$ for $5 \mathrm{~min}$ with the specific primer pairs as above. $512 \mathrm{bp} \mathrm{PCR}$ amplicons were digested by restriction enzymes RsaI and Alw441. Digestion with RsaI resulted in 396 bp and 116 bp fragments in mutated allele while digestion with Alw441 produced products of $397 \mathrm{bp}$ and $115 \mathrm{bp}$ in normal allele. Products were checked on $2 \%$ agarose gel.

\section{Analysis for RPGR deletion causing XLPRA by fragment analysis}

The ORF15 sequence was amplified by PCR using HEX fluorescence labeled specific primers. These primers were selected from a reference article [3] for mutation analysis; for XLPRA1, 5'AAGGGGAGGAGAAAGGGGAGGCT3' and 5'TCССТСТTССТССТССССТTСАТАЗ' were used as forward and reverse primers respectively. For XLPRA2, forward and reverse primers sequences were 5'AAGGGGAGGAGAAAGGGGAGGCT3' and 5'TCCCCTACTTCCTCTTCCCTCTCA3' correspondingly. PCR was carried out under the conditions of $98^{\circ} \mathrm{C}$ for $10 \mathrm{sec}$ and then $30 \mathrm{cycles}$ of $98^{\circ} \mathrm{C}$ for $2 \mathrm{sec}, 57^{\circ} \mathrm{C}$ for $30 \mathrm{sec}, 72^{\circ} \mathrm{C}$ for $15 \mathrm{sec}$ and $72^{\circ} \mathrm{C}$ for $1 \mathrm{~min}$ with the primer pairs listed above. Then deletion was detected by fragment size analysis using ABI PRISM 310 Genetic Analyzer.

\section{Results and Discussion}

Our data shows that of all PRCD amplified from PRA positive samples are of same size as normal/control. We did not observe any indels. Restriction fragment length polymorphism study demonstrated that all samples, excluding 3 Cocker spaniel and 3 Labrador Retriever, lacked point mutation at the interest site. Point mutation at the site should facilitate RsaI digestion. Furthermore, these RsaI undigested DNA fragments presented Alw441 restriction site as normal, Figure 1(A). This confirms presence of nucleotide ' $G$ ' at $5 \mathrm{bp}$ position, like unaffected.

Moreover, our study on Cocker Spaniel and Labrador Retriever: breeds with known association of PRA and PRCD confirmed presence of RsaI and lack of Alw441 restriction site in $P R C D$, Figure 1(B). Our results are in accordance with previous studies by [5]. These $P R C D$ positive samples were of average age $7.33(8,7,7)$ years for Cocker Spaniel and $5.33(6,5,5)$ years for Labrador Retriever. This fits with normal late onset scenario for PRA-prcd. From the data, we can suggest that 3 Cocker spaniels and 3 Labrador Retriever were PRA positive: PRA-prcd variant.

$P R C D$ is believed to be an important protein coding gene. Even though, this point mutation does not alter secondary structure of the coded protein, it must be affecting recognition site provided by this protein [3]. Moreover, high level of conservation of this protein in all vertebrates suggest, that the protein must play an important role in metabolism or photoreceptor structure exclusive to vertebrates [3]. Thus, abnormalities to this gene can lead to visual imperfection.

As an additional study, these dogs were accessed for X-Linked PRA. We accessed the samples for two known XLPRA; XLPRA1 and XLPRA2. Agarose gel electrophoresis and capillary electrophoresis results revealed that all 22 PRA positive samples are free from XLPRA1 \& XLPRA2 (Figures 2 and 3). This is because we did not observe any

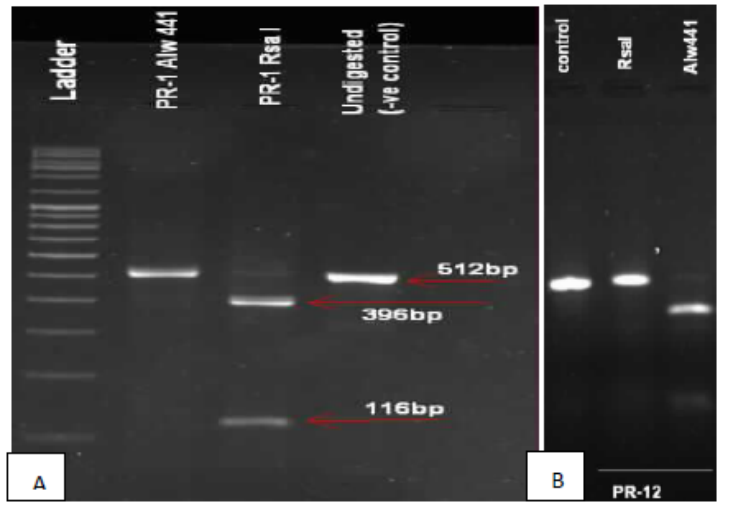

Figure 1: Representative Restriction Digest test of $P R C D$ gene; (A) $P R C D$ positive sample. DNA ladder $(2 \mu \mathrm{l})$. Digested, undigested and control sample $(10 \mu \mathrm{l})$. (B) $P R C D$ negative sample. Digested, undigested and control sample $(10 \mu \mathrm{l})$.

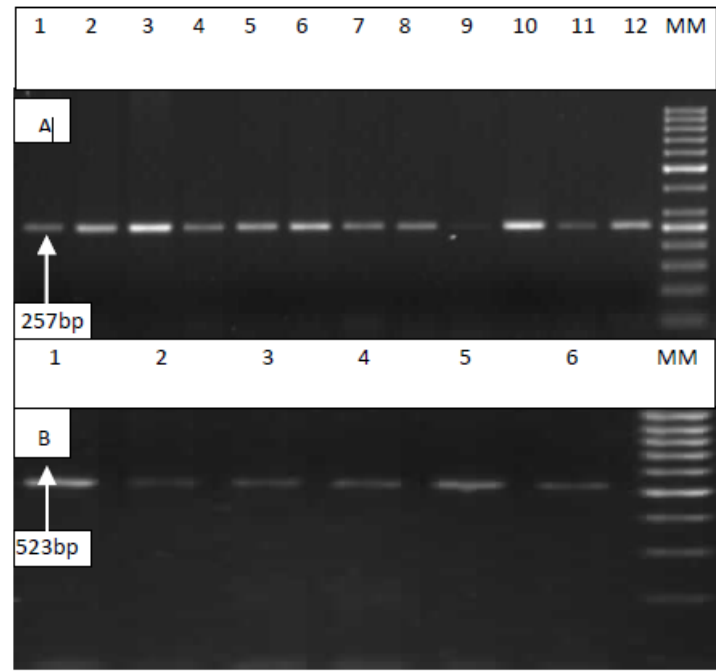

Figure 2: Representative electrophoresis gel of RPGR PCR for (A) XLPRA detection (257/252 bp). Well 1-12 are

Loaded with amplified RPGR of sample PR-1 to $12(5 \mu \mathrm{l})$. MM: GeneRulerTM 50 bp DNA ladder, 50-1000 bp (Fermentas) $(2 \mu \mathrm{l})$. (B) XLPRA2 detection $(523 / 521$ bp). Well $1-6$ are loaded with Pomeranian (well 1-2), Labrador retriever (well 3-4) and Cocker spaniel (well 5-6) (5 $\mu$ l each). MM: MassRuler ${ }^{\mathrm{TM}}$ Low Range DNA Ladder, 80-1031 bp (Fermentas) $(2 \mu \mathrm{l})$. 
Citation: Dave U, Dave CJ (2014) Involvement of PRCD and RPGR Genes in Progressive Retinal Atrophy in Locally Bred Canines. J Mol Biomark Diagn 5: 161. doi:10.4172/2155-9929.1000161

Page 3 of 4

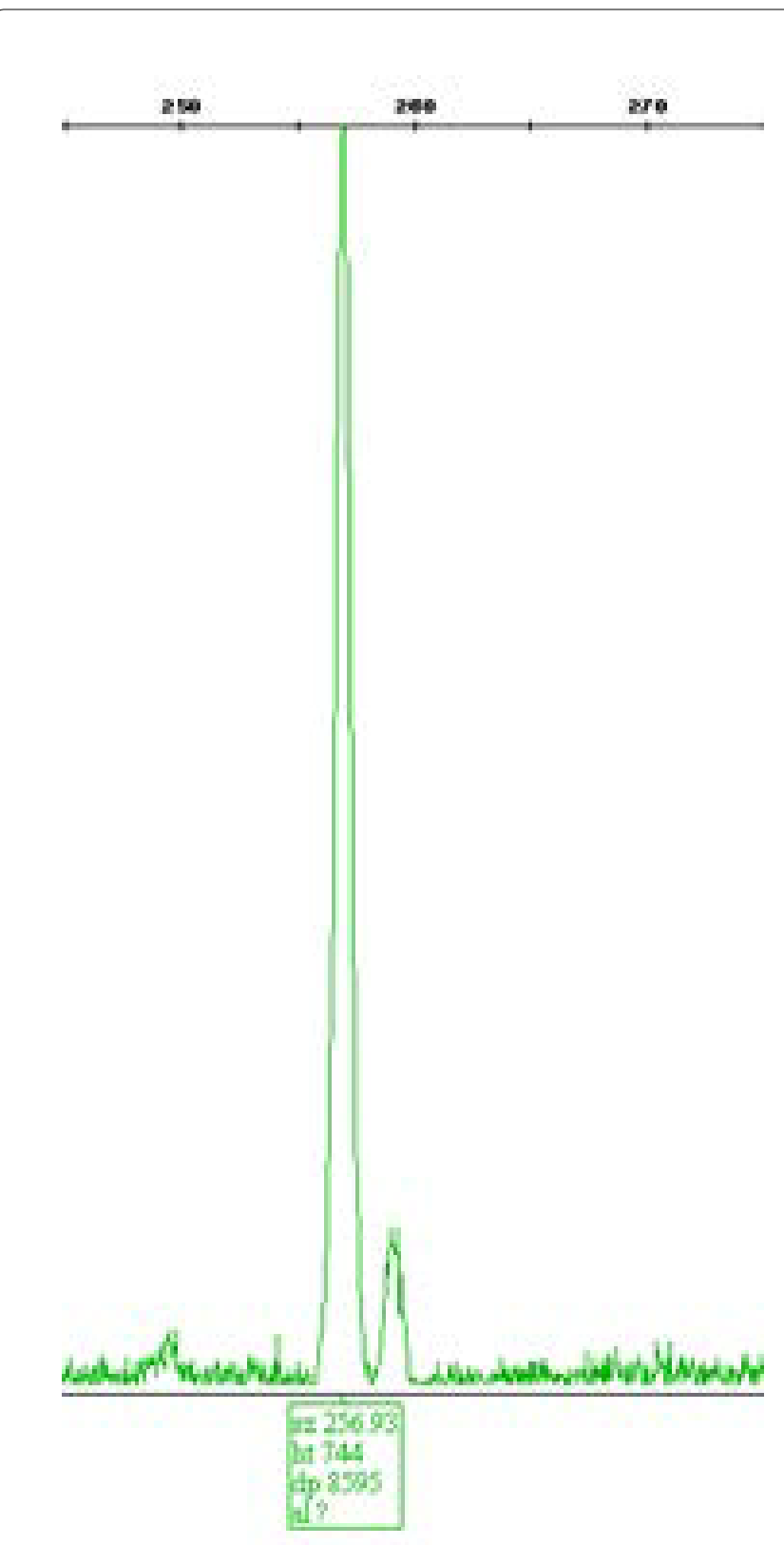

Figure 3: Capillary gel electrophoresis, fragment analysis of XLPRA1 by 310 ABI-PRISM. Peak of 744 FU intensity at 256.93 (257 bp).

size variation in the product, when compared to reported size. In these circumstances, it is very tempting to conclude that none of PRA positive dogs has XLPRA. Nevertheless, most recent study has suggested that there has to be a third kind of X-Linked PRA (XLPRA3), especially in Border collie [5], but exact mutation is still unknown. Besides, the gene is also found with neutral mutation in Red wolves; a member of canine family [3]. Therefore, it can be suggested that study samples do not have XLPRA1 or XLPRA2, but it cannot be confirmed whether they have X-Linked PRA or not.

Sequencing of PCR products and linkage analysis can ascertain XLPRA positive or negative status for the samples studied. This suggested further work should also support our finding on PRA-prcd [12-16].

\section{Conclusion}

From our data, we propose that in all tested Pomeranian and Mongrel PRCD mutation is not linked to PRA. Larger sample size could firmly allow exclusion of Pomeranian from future $P R C D$ tests. In spite, we suggest further work of sequencing the gene to identify any other undetected anomalies contributing to the disease. Additionally, in agreement to previous study on Cocker Spaniel and Labrador Retriever, we find mutation in PRCD of PRA positive dogs.

We also elucidate that all tested dogs are free from XLPRA1 and XLPRA2.

\section{Only good if you get XLPRA positive. Rpgr}

It was proposed that the purine-rich region may adopt unusual non B-DNA conformations and show sequence motifs similar to DNA polymerase-a arrest sites found near other deletion hotspots; this can lead to micro deletions following slipped-strand mispairing events. We have found similar micro deletions in the present study, suggesting that RPGR exon ORF15 appears to be a mutation hotspot in canids. Our studies demonstrate that the nature of the RPGR exon ORF15 deletions determine the retinal phenotype. Both disorders are distinct, and have remained so even though the diseases now are present in mixed-breed dogs of the same genetic background.

\section{References}

1. Patterson DF (2000) Companion animal medicine in the age of medical genetics. J Vet Intern Med 14: 1-9.

2. Aguirre GD, Acland GM (2006) Models, mutants and man: searching for unique phenotypes and genes in the dog model of inherited retinal degeneration, in E.A. The Dog and Its Genome. Cold Spring Harbor Laboratory Press, Cold Spring Harbor, NY, USA.

3. Zangerl B, Johnson JL, Acland GM, Aguirre GD (2007) Independent origin and restricted distribution of RPGR deletions causing XLPRA. J Hered 98: 526-530.

4. Zeiss CJ, Acland GM, Aguirre GD (1999) Retinal pathology of canine X-linked progressive retinal atrophy, the locus homologue of RP3. Invest Ophthalmol Vis Sci 40: 3292-3304.

5. Vilboux T, Chaudieu G, Jeannin P, Delattre D, Hedan B, et al. (2008) Progressive retinal atrophy in the Border Collie: a new XLPRA. BMC Vet Res 4: 10.

6. Zangerl B, Goldstein O, Philp AR, Lindauer SJ, Pearce-Kelling SE, et al (2006) Identical mutation in a novel retinal gene causes progressive rod-cone degeneration in dogs and retinitis pigmentosa in humans. Genomics 88: 551 563.

7. Werner P, Raducha MG, Prociuk U, Henthorn PS, Patterson DF (1997) Physical and linkage mapping of human chromosome 17 loci to dog chromosomes 9 and 5. Genomics 42: 74-82.

8. Ray K, Wang W, Czarnecki J, Zhang Q, Acland GM, et al. (1999) Strategies for identification of mutations causing hereditary retinal diseases in dogs: evaluation of opsin as a candidate gene. J Hered 90: 133-137.

9. Zhang Q, Acland GM, Wu WX, Johnson JL, Pearce-Kelling S, et al. (2002) Different RPGR exon ORF15 mutations in Canids provide insights into photoreceptor cell degeneration. Hum Mol Genet 11: 993-1003.

10. Zito I, Downes SM, Patel RJ, Cheetham ME, Ebenezer ND, et al. (2003) RPGR mutation associated with retinitis pigmentosa, impaired hearing, and sinorespiratory infections. J Med Genet 40: 609-615.

11. Guyon R, Pearce-Kelling SE, Zeiss CJ, Acland GM, Aguirre GD (2007) Analysis of six candidate genes as potential modifiers of disease expression in canine XLPRA1, a model for human X-linked retinitis pigmentosa 3. Mol Vis 13: 10941105.

12. Lahiri DK, Nurnberger JI Jr (1991) A rapid non-enzymatic method for the preparation of HMW DNA from blood for RFLP studies. Nucleic Acids Res 19: 5444.

13. Zeiss CJ, Ray K, Acland GM, Aguirre GD (2000) Mapping of X-linked progressive retinal atrophy (XLPRA), the canine homolog of retinitis pigmentosa 3 (RP3). Hum Mol Genet 9: 531-537. 
Citation: Dave U, Dave CJ (2014) Involvement of PRCD and RPGR Genes in Progressive Retinal Atrophy in Locally Bred Canines. J Mol Biomark Diagn 5: 161. doi:10.4172/2155-9929.1000161

Page 4 of 4

14. Gu W, Ray K, Pearce-Kelling S, Baldwin VJ, Langston AA, et al. (1999) Evaluation of the APOH gene as a positional candidate for prod in dogs. Invest Ophthalmol Vis Sci 40: 1229-1237.

15. Acland GM, Ray K, Mellersh CS, Gu W, Langston AA, et al. (1998) Linkage analysis and comparative mapping of canine progressive rod-cone degeneration (prcd) establishes potential locus homology with retinitis pigmentosa (RP17) in humans. Proc Natl Acad Sci U S A 95: 3048-3053.

16. Goldstein O, Zangerl B, Pearce-Kelling S, Sidjanin DJ, Kijas JW, et al. (2006) Linkage disequilibrium mapping in domestic dog breeds narrows the progressive rod-cone degeneration interval and identifies ancestral diseasetransmitting chromosome. Genomics 88: 541-550. 